\title{
Predictors of Outcome After Mechanical Thrombectomy in Stroke Patients Aged $\geq 85$ Years
}

\author{
Laurent Derex, Julie Haesebaert, Céline Odier, Walid Alesefir, Yves Berthezène, \\ Marielle Buisson, Nicole Daneault, Yan Deschaintre, Omer Faruk Eker, \\ Laura Gioia, Dana Iancu, Grégory Jacquin, Fatine Karkri, Marlène Lapierre, \\ Norbert Nighoghossian, Jean Raymond, Daniel Roy, Christian Stapf, Alain Weill, \\ Alexandre Y. Poppe (i)
}

ABSTRACT Background: The effectiveness of mechanical thrombectomy (MT) in elderly stroke patients remains debated. We aimed to describe outcomes and their predictors in a cohort of patients aged $\geq 85$ years treated with MT. Methods: Data from consecutive patients aged $\geq 85$ years undergoing MT at two stroke centers between January 2016 and November 2019 were reviewed. Admission National Institutes of Health Stroke Scale (NIHSS), pre-stroke, and 3-month modified Rankin scale (mRS) were collected. Successful recanalization was defined as modified thrombolysis in cerebral ischemia score $\geq 2 \mathrm{~b}$. Good outcome was defined as mRS $0-3$ or equal to pre-stroke mRS at 3 months. Results: Of 151 included patients, successful recanalization was achieved in $74.2 \%$. At 3 months, $44.7 \%$ of patients had a good outcome and 39\% had died. Any intracranial hemorrhage (ICH) and symptomatic ICH occurred in 20.3\% and 3.6\%, respectively. Logistic regression analysis identified lower pre-stroke mRS score (adjusted odds ratio [aOR], 0.52; 95\% CI, 0.36-0.76), lower admission NIHSS score (aOR, 0.90; 95\% CI, 0.83-0.97), successful recanalization (aOR, 3.65; 95\% CI, 1.32-10.09), and absence of ICH on follow-up imaging (aOR, 0.42; 95\% CI, 0.08-0.75), to be independent predictors of good outcome. Patients with successful recanalization had a higher proportion of good outcome $(45.3 \%$ vs $34.3 \%, \mathrm{p}=0.013)$ and lower mortality at 3 months $(35.8 \%$ vs $48.6 \%$, $\mathrm{p}=0.006$ ) compared to patients with unsuccessful recanalization. Conclusions: Among patients aged $\geq 85$ years, successful recanalization with MT is relatively common and associated with better 3-month outcome and lower mortality than failed recanalization. Attempting to achieve recanalization in elderly patients using MT appears reasonable.

RÉSUMÉ : Prédicteurs de l'évolution de l'état de santé de patients âgés de 85 ans et plus victimes d'un AVC qui ont bénéficié d'une thrombectomie mécanique. Contexte : L'efficacité de la thrombectomie mécanique (TM) chez des patients âgés ayant été victimes d'un AVC continue à être sujette à débat. Nous voulons donc décrire ici l'évolution de leur état de santé et les prédicteurs qui y sont liés. Pour ce faire, notre étude a reposé sur une cohorte de patients âgés de 85 ans et plus qui ont bénéficié d'un traitement de TM. Méthodes : Nous avons ainsi passé en revue les données de patients qui ont bénéficié d'une TM dans deux établissements hospitaliers spécialisés dans les AVC, et ce, de janvier 2016 à novembre 2019 . À cet égard, ont été collectés leurs scores à la National Institutes of Health Stroke Scale (NIHSS) au moment de leur admission mais aussi leurs résultats obtenus à la Modified Rankin Scale (MRS) avant leur AVC et 3 mois après qu'il est survenu. Nous avons par ailleurs établi qu'une recanalisation menée avec succès correspondait à un score de $\geq 2 \mathrm{~b}$ à la suite d'une thrombolyse liée à un cas d'ischémie cérébrale. De plus, une évolution satisfaisante de l'état de santé des patients a été définie par un score à la MRS de 0-3 ou par un score au troisième mois égal à celui d'avant un AVC. Résultats : Sur les 151 patients inclus dans cette étude, une recanalisation réussie a été obtenue chez 74,2 \% d'entre eux. Au troisième mois, 44,7\% des patients avaient vu leur état de santé évoluer de façon favorable alors que $39 \%$ d'entre eux sont décédés. Des cas d'hémorragie intracrânienne (HIC) et de HIC symptomatique sont par ailleurs survenus respectivement chez 20,3\% et 3,6\% des patients. C'est au moyen d'une analyse de régression logistique que nous avons déterminé que de faibles scores à la MRS avant un AVC (rapport de cotes ajusté [RCA] 0,52; IC 95\% 0,36-0,76), de faibles scores à la NIHSS au moment d'une admission (RCA 0,90; IC $95 \%$ 0,83-0,97), des recanalisations réussies (RCA 3,65 ; IC $95 \%$ 1,32-10,09) et l'absence de HIC lors d'IRM de suivi (RCA 0,42 ; IC 95 $\%$ 0,08-0,75) étaient de bons prédicteurs indépendants d'un état de santé évoluant favorablement. À ce sujet, les patients dont la recanalisation a été réussie ont été plus nombreux à voir leur état de santé évoluer favorablement $(45,3 \%$ contre $34,3 \% ; p=0,013)$ et moins susceptibles de décéder au troisième mois $(35,8 \%$ contre $48,6 \% ; p=0,006)$ si on les compare aux patients dont la recanalisation s'est soldée par un échec. Conclusions : Parmi les patients âgés de 85 ans et plus, on a donc observé que les recanalisations réussies au moyen de la TM sont passablement courantes et associés, au troisième mois, à une évolution plus favorable de leur état de santé et à un taux de décès plus faible. Bref, opter pour la recanalisation chez des patients âgés en utilisant la TM semble somme toute une avenue raisonnable.

From the Stroke Centre, Department of Neurology, Neurological Hospital, Hospices Civils de Lyon, Lyon, France (LD, NN); Université de Lyon, Université Claude Bernard Lyon 1, HESPER EA 7425, Lyon, France (LD, JH); Hospices Civils de Lyon, Pôle de Santé Publique, Lyon, France (JH); Department of Medicine (Neurology), Centre Hospitalier de l'Université de Montréal (CHUM), Montréal, Québec, Canada (CO, WA, ND, YD, LG, GJ, FK, ML, CS, AYP); Department of Neuroradiology, Neurological Hospital, Hospices Civils de Lyon, Lyon, France (YB, OFE); Clinical Investigation Center, INSERM 1407, Louis Pradel Hospital, Hospices Civils de Lyon, Lyon, France (MB); Department of Radiology (Neuroradiology), Centre Hospitalier de l'Université de Montréal (CHUM), Montréal, Québec, Canada (DI, JR, DR, AW); and Neurovascular Group, Axe Neurosciences, Centre de Recherche du Centre Hospitalier de l'Université de Montréal, Montréal, Québec, Canada (CS, AYP)

Received November 27, 2020. Final Revisions Submitted January 29, 2021. Date of Acceptance February 21, 2021

Correspondence to: Alexandre Y. Poppe, Department of Medicine (Neurology), Centre Hospitalier de l'Université de Montréal, 900 rue St-Denis, Bureau R04-758, Montréal, Québec H2X 3H8, Canada. Email: alexandre.poppe.med@ssss.gouv.qc.ca 
Keywords: Elderly, Ischemic stroke, Mechanical thrombectomy, Reperfusion

doi:10.1017/cjn.2021.37

Can J Neurol Sci. 2022; 49: 49-54

\section{INTRODUCTION}

The effectiveness of mechanical thrombectomy (MT) for acute ischemic stroke (AIS) in octogenarians and nonagenarians remains debated. The Highly Effective Reperfusion Evaluated in Multiple Endovascular Stroke Trials meta-analysis of individual patientlevel data from five randomized controlled trials (RCTs) showed that AIS patients aged $\geq 80$ years benefit from MT compared to standard medical therapy. ${ }^{1}$ However, this meta-analysis included only $198(15 \%)$ patients aged $\geq 80$ years from a pooled total of 1278 patients, as elderly patients were either excluded from RCTs or under-represented. Indeed, three of the six major trials excluded older patients. ${ }^{2-4}$ Data on clinical outcome, intracranial hemorrhage (ICH), and procedural complications following MT in patients aged $\geq 85$ years remain limited, while the proportion of stroke patients in this age group is increasing. ${ }^{5-8}$ We hypothesized that MT achieves good outcomes in patients aged $\geq 85$ years and aimed to identify predictors of outcome at 3 months in this patient population, using a large two-center cohort.

\section{Methods}

\section{Patient Selection}

This observational study retrospectively analyzed clinical and imaging data prospectively gathered from two comprehensive academic stroke centers (Centre Hospitalier de l'Université de Montréal, Québec, Canada; Neurological Hospital, Hospices Civils de Lyon, France) between January 2016 and November 2019. We included all patients aged $\geq 85$ years treated by MT for an AIS with large vessel occlusion. This age cutoff was used since patients aged $>85$ years were excluded from several MT trials and therefore data on MT in elderly patients derived from these trials include few patients over $85 .^{1}$

There were no systematic exclusion criteria based on prestroke modified Rankin scale (mRS) and National Institute of Health Stroke Scale (NIHSS) scores or extent of infarction on baseline imaging.

\section{Neurovascular Imaging and Interventional Procedure}

All patients underwent either computed tomography (CT) and CT-angiography or magnetic resonance imaging (MRI) and MR-angiography before MT. Repeat brain imaging using CT or MRI was performed 24-36 hours after MT or earlier in cases of clinical deterioration. On follow-up imaging, ICH was classified according to the European Cooperative Acute Stroke Study II criteria. ${ }^{9}$ Symptomatic hemorrhage was defined as any $\mathrm{ICH}$ associated with neurological deterioration (NIHSS score increase of $\geq 4$ points). An experienced neuroradiologist reviewed pre-treatment CT or diffusion-weighted MRI images and recorded the Alberta Stroke Program Early CT (ASPECT) score. ${ }^{10}$ The occlusion site was assessed on the initial angiogram before MT. Patients were treated with aspiration catheters, stent retrievers, or a combination of both techniques. The choice of device was left to operator discretion. Embolism in a new territory was defined as a thromboembolic migration in a previously unaffected artery during the endovascular procedure. At the end of the procedure, the neuro-interventionalist determined a final modified thrombolysis in cerebral ischemia (mTICI) score. Successful recanalization was defined as an mTICI grade of $2 b$ (perfusion with incomplete [ $\geq 50 \%$ ] distal branch filling) or 3 (full perfusion with filling of all distal branches) on the final angiogram.

\section{Data Collected}

Baseline data on demographic characteristics (age, sex) and stroke risk factors (current smoking, hypertension, hyperlipidemia, atrial fibrillation, and diabetes mellitus) were collected at hospital admission. Neurological status was assessed using NIHSS score at admission. Pre-stroke functional status was assessed with the mRS score. Time from admission to initiation of intravenous thrombolysis with recombinant tissue-type plasminogen activator, to groin puncture, and to recanalization was recorded. Clinical outcome was assessed by the 90-day mRS score during a face-to-face neurological follow-up visit or via a structured telephone interview performed by an mRS-certified stroke research nurse.

\section{Outcome Definitions}

The 90-day mRS was used as the primary clinical outcome and was dichotomized into good outcome (mRS score $\leq 3$ or equal to pre-stroke value) and poor outcome (mRS score 4-6). This outcome is aligned with other studies of elderly patients undergoing MT that have also defined a good outcome as an mRS of $0-3$, given the higher levels of baseline disability in this population. $^{7,8}$ The more conventional outcome of mRS score $\leq 2$ or equal to pre-stroke value, termed favorable, was analyzed as a secondary outcome.

Other descriptive secondary outcomes were the proportion of patients with any $\mathrm{ICH}$, symptomatic ICH, procedural complications (including intracranial arterial perforation, iatrogenic dissection, embolic event in a new territory, and groin hematoma), and death.

\section{Statistical Analysis}

Statistics were performed using SAS software 9.4 version (SAS Institute Inc., Cary, NC, USA). Categorical variables are displayed as the number and percentage of patients (n, \%), and quantitative variables are presented as the median and interquartile range.

We explored factors associated with good outcome using univariate and multivariate stepwise logistic regression. Crude and adjusted odds ratios (aOR) are given with their $95 \%$ confidence interval $(95 \% \mathrm{CI})$. We used a structured approach to select 
Table 1 Baseline characteristics, procedural times, and 3-month outcome of all patients

\begin{tabular}{|c|c|}
\hline Characteristics & All patients $(n=151)$ \\
\hline Age, year, median (Q1-Q3, IQR) & $88.0(86-89.3)$ \\
\hline Men & $37(24.5)$ \\
\hline \multicolumn{2}{|l|}{ Medical history } \\
\hline Hypertension $^{*}$ & $116(77.3)$ \\
\hline Diabetes mellitus $^{*}$ & $20(13.3)$ \\
\hline Hypercholesterolemia $^{*}$ & $56(37.3)$ \\
\hline Current smoking ${ }^{*}$ & $7(4.7)$ \\
\hline Atrial fibrillation ${ }^{*}$ & $83(55.3)$ \\
\hline \multicolumn{2}{|l|}{ Neurological and functional status } \\
\hline NIHSS score, median (Q1-Q3, IQR) & $19.0(14-26.9)$ \\
\hline $\begin{array}{l}\text { Pre-stroke mRS score, median (Q1-Q3, } \\
\text { IQR) }\end{array}$ & $1.0(0-3,2.0)$ \\
\hline \multicolumn{2}{|l|}{ Pre-stroke mRS score } \\
\hline 0 & $52(34.7)$ \\
\hline 1 & $27(18.0)$ \\
\hline 2 & $35(23.3)$ \\
\hline 3 & $33(22.0)$ \\
\hline 4 & $3(2.0)$ \\
\hline \multicolumn{2}{|l|}{ Imaging } \\
\hline ASPECTS, median (Q1-Q3, IQR) $^{* * *}$ & $9.0(8-10.2)$ \\
\hline \multicolumn{2}{|l|}{ Occluded vessel } \\
\hline M1-MCA & $96(63.6)$ \\
\hline Intracranial ICA & $34(22.5)$ \\
\hline Other & $21(13.9)$ \\
\hline \multicolumn{2}{|l|}{$\begin{array}{l}\text { Procedural times, min, median (Q1-Q3, } \\
\text { IQR) }\end{array}$} \\
\hline Admission to IV r-tPA $(\mathrm{n}=68)$ & $42(22-77,27)$ \\
\hline Admission to groin puncture $(\mathrm{n}=148)$ & $39(16-91,48)$ \\
\hline Admission to recanalization $(\mathrm{n}=117)$ & $75(52-101,49)$ \\
\hline \multicolumn{2}{|l|}{ 3-month mRS score $(n=141)$} \\
\hline 0 & $6(4.3)$ \\
\hline 1 & $11(7.8)$ \\
\hline 2 & $21(14.9)$ \\
\hline 3 & $22(15.6)$ \\
\hline 4 & $19(13.5)$ \\
\hline 5 & $7(5.0)$ \\
\hline 6 & $55(39.0)$ \\
\hline
\end{tabular}

ASPECTS = Alberta Stroke Program Early CT Score; ICA = internal carotid artery; IQR = interquartile range; IV r-tPA = intravenous recombinant tissue-type plasminogen activator; $\mathrm{MCA}=$ middle cerebral artery; $\mathrm{mRS}=$ modified Rankin scale; NIHSS $=$ National Institutes of Health Stroke Scale.

Values expressed as n/total n (\%) unless otherwise indicated.

*1 missing data $(\mathrm{n}=150)$.

** 5 missing data $(n=146)$. variables to be included in the multivariate model, associating literature search and exchange between experts in order to identify the relationships between the variables and include relevant factors in the model (patient and stroke characteristics). We entered in the multivariate model baseline demographic, clinical, and radiological characteristics (age, sex, center, pre-stroke mRS, NIHSS and ASPECT scores, and occlusion site), stroke risk factors, procedural variables (intravenous thrombolysis, successful recanalization, and time from admission to groin puncture), and ICH as explanatory variables. Interactions were tested and multicollinearity was screened using the COLLIN option on SAS. Significance level was set at $\alpha=0.05$.

\section{Results}

From January 2016 to November 2019, 151 patients aged $\geq 85$ years (median age 88 years) were consecutively treated by MT at the two participating centers. Main patient and treatment characteristics are reported in Table 1. Intravenous thrombolysis was administered before MT in 55\% (83 of 151) of patients.

\section{Procedural Outcomes}

Successful recanalization (mTICI $\geq 2 b$ ) was achieved in $74.2 \%$ (112 of 151). Baseline characteristics (age, sex, NIHSS and ASPECT scores, occlusion site, rate of intravenous thrombolysis) were not different according to successful recanalization status, apart from pre-stroke mRS score, which was higher in patients with successful recanalization (median [Q1-Q3], 1 [0-2] vs $2[0-3]$ in patients with successful recanalization, $p=0.049)$.

Procedural complications occurred in $14.5 \%$ (17 of 117) of patients: there was 1 intracranial arterial perforation, 2 embolic events in a new territory, 5 iatrogenic dissections, and 11 groin hematomas.

On follow-up imaging, any ICH and symptomatic ICH occurred in $20.3 \%$ (28 of 138) and 3.6\% (5 of 138) of patients, respectively.

\section{Functional Outcome and Death}

Ten patients were lost to follow-up despite several telephone attempts and were therefore excluded from the final functional outcome analysis. These patients had similar baseline characteristics (age, sex, pre-stroke mRS, NIHSS and ASPECT scores) as included patients (data not shown).

At 90 days, 33.3\% (47 of 141) of all patients had a favorable functional outcome ( $\mathrm{mRS}$ score $\leq 2$ or equal to pre-stroke value), $44.7 \%$ (63 of 141) had a good functional outcome (mRS score $\leq 3$ or equal to pre-stroke value), and $39.0 \%$ (55 of 141) had died.

Figure 1 provides an overview of mRS distribution at 90 days for the overall cohort and according to final recanalization status. Patients with successful recanalization had a significantly higher rate of good functional outcome ( $\mathrm{p}=0.013)(45.3 \%$ [48 of 106] vs $34.3 \%$ [12 of 35]) and a significantly lower mortality rate at 90 days $(\mathrm{p}=0.006)(35.8 \%$ [38 of 106] vs $48.6 \%$ [17 of 35]) as compared to patients with failed recanalization $(\mathrm{mTICI} \leq 2 \mathrm{a})$. Notably, $54.7 \%$ (58 of 106) of patients had an unfavorable outcome despite successful recanalization (so-called "futile recanalization"). 


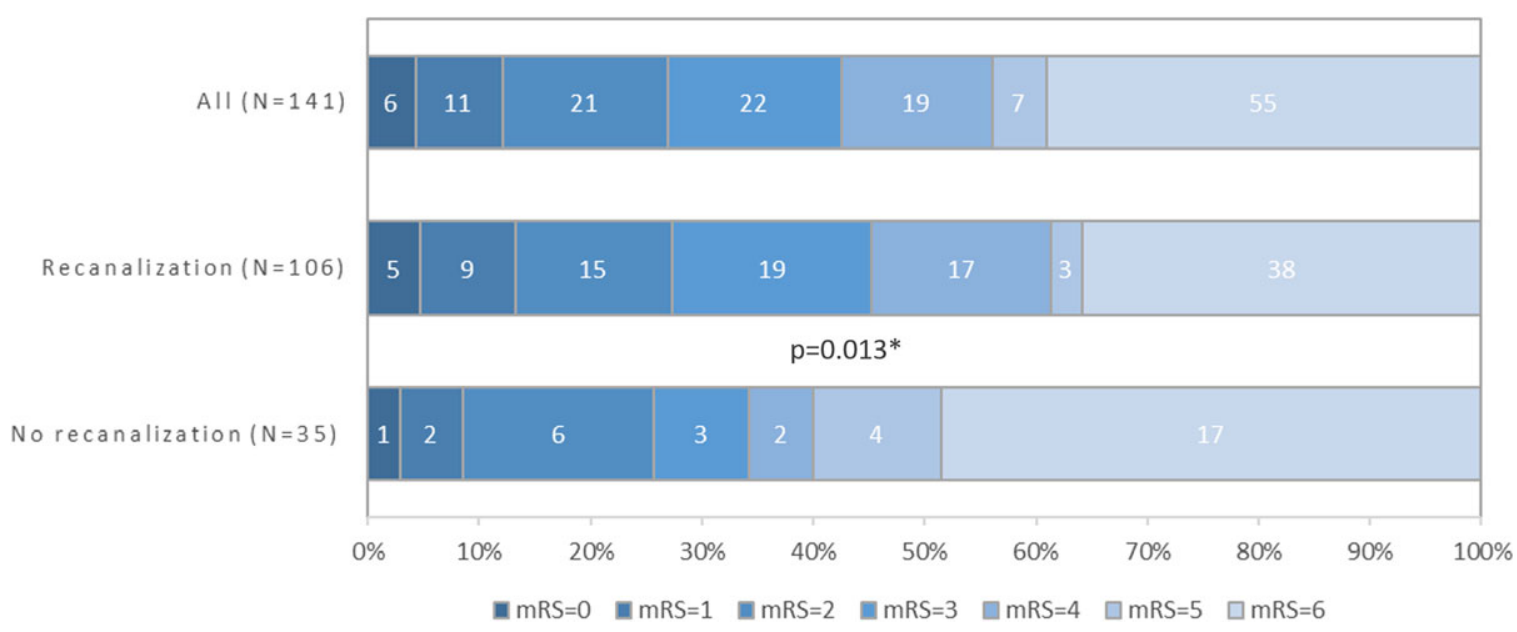

Figure 1: Distribution of 3-month modified Rankin scale $(m R S)$ score according to successful recanalization status. Successful recanalization was defined as modified TICI $2 \mathrm{~b} / 3$ at the end of the endovascular procedure. *Adjusted p value for good outcome (3-month mRS score 0-3 or equal to pre-stroke value) is reported, multivariate stepwise regression model (Table 2).

In univariate analysis, lower NIHSS score at admission $(\mathrm{p}<0.001)$, lower pre-stroke mRS score $(\mathrm{p}<0.001)$, middle cerebral artery M1 segment occlusion site as opposed to other occlusion sites $(p=0.043)$, shorter time from admission to groin puncture $(\mathrm{p}=0.046)$, and absence of ICH on follow-up imaging $(\mathrm{p}=0.007)$ were predictors of good functional outcome $(\mathrm{mRS} \leq$ 3 or equal to pre-stroke value) at 90 days. After multivariate analysis, lower NIHSS score at admission (aOR, 0.90; 95\% CI, $0.83-0.97 ; \mathrm{p}=0.013$ ), lower pre-stroke mRS score (aOR, 0.52; 95\% CI, 0.36-0.76; $\mathrm{p}<0.001)$, successful recanalization $(\mathrm{aOR}$, $3.65 ; 95 \%$ CI, 1.32-10.09; $\mathrm{p}=0.013$ ), and absence of ICH on follow-up imaging (aOR, 0.42; 95\% CI, 0.08-0.75; $\mathrm{p}=0.013$ ) remained as independent predictors of good functional outcome (Table 2). For favorable outcome (mRS $\leq 2$ or equal to pre-stroke value), multivariate analysis yielded similar results, with the exception of successful recanalization, which was not associated with outcome (Supplementary Data).

\section{Discussion}

In this large cohort of consecutive AIS patients aged $\geq 85$ years treated with MT, we found that successful recanalization is associated with a higher rate of good outcome and a lower rate of mortality at 90 days. This suggests that attempting to achieve recanalization in elderly patients using MT is worthwhile. A recent analysis of the MR CLEAN Registry has shown that successful recanalization was more strongly associated with a shift toward good functional outcome in older adults than in younger patients. ${ }^{11}$

With a sample size of 151 patients aged $\geq 85$ years, our study is one of the largest in the field. Most patients were women (75.5\%), related to the higher life expectancy of women, and a majority had atrial fibrillation. Regarding the risk of symptomatic $\mathrm{ICH}$ and procedural complications, our results are in line with the results of previously published RCTs. ${ }^{1,12}$

Good functional outcome at 90 days was observed in $44.7 \%$ of patients. This is less than what was observed in most major MT RCTs, further suggesting that the rate of good outcome after MT declines with increasing age, ${ }^{6,11,13}$ particularly in a "realworld setting". Like others, ${ }^{7,8}$ we defined good functional outcome as an $\mathrm{mRS}$ score $\leq 3$ or equal to pre-stroke value as it represents a reasonable outcome in an elderly population $(24 \%$ of our patients had a pre-stroke mRS score $\geq 3$ ). In elderly patients, a preserved ability to walk without the help of another person is an important determinant of relative functional independence and both mRS 2 and 3 have been found to be associated with similar health-related quality of life. ${ }^{14}$ A high 90-day mortality rate $(39 \%)$ was also observed in our study, while large cohorts of younger patients treated by MT have shown mortality rates closer to $20 \%$. $^{1}$ This high mortality likely reflects the frailty of the elderly population, with its higher burden of pre-stroke medical comorbidities and its increased susceptibility to developing post-stroke complications, ${ }^{8}$ but may also be related to higher rates of early limitation of care orders as compared to younger patients. Consequently, and somewhat reassuringly, we observed a relatively low rate $(18.4 \%)$ of patients surviving at 3 months with moderately severe or severe disability (mRS score 4-5), fear of which might drive some physicians to withhold MT from elderly patients.

In our analysis, most predictors of good outcome, including pre-stroke mRS and NIHSS scores, were readily available at admission, emphasizing that decision-making for MT in this age group should be made on an individual basis, with particular consideration of patient's pre-stroke level of disability. The influence of baseline clinical severity on functional outcome after MT in octogenarians has been suggested by others as well. ${ }^{15}$

Importantly, our data show that successful recanalization is an independent predictor of good functional outcome and is associated with a significant reduction of mortality at 90 days. A recent retrospective analysis of 124 nonagenarians treated with MT highlighted that only patients with successful recanalization after the first thrombectomy device pass had an increased rate of good outcome and a reduced 90-day mortality. ${ }^{7}$ In our series, successful recanalization was achieved in $74.2 \%$ of cases. A similar relatively low rate of recanalization $(78.2 \%)$ was observed among nonagenarians, ${ }^{7}$ while recent series of younger patients have reported recanalization rates of up to $95 \%$. ${ }^{16}$ These lower rates of recanalization among patients aged $\geq 85$ years may be explained by difficult thrombus access related to age-associated vessel tortuosity, failed thrombus retrieval, ${ }^{8,17}$ or earlier 
Table 2 Univariate and multivariate logistic regression of factors associated with good outcome (3-month modified Rankin scale score $\leq \mathbf{3}$ or equal to pre-stroke value)

\begin{tabular}{|c|c|c|c|c|c|c|}
\hline Characteristics & $\begin{array}{c}\text { 3-month } \mathrm{mRS} \leq 3 \\
\text { or pre-stroke } \\
(\mathbf{n}=63)\end{array}$ & $\begin{array}{l}\text { 3-month mRS }>3 \\
\quad(n=78)\end{array}$ & p-Value & $\begin{array}{l}\text { Crude OR }(95 \% \\
\text { CI) }\end{array}$ & $\begin{array}{l}\text { Adjusted OR } \\
\qquad(95 \% \text { CI) }\end{array}$ & $\mathbf{p}$ \\
\hline Age, year, median (Q1-Q3) & $87(86-89)$ & $88(86-91)$ & 0.060 & $0.85(0.74-0.96)$ & & NS \\
\hline Men & $15(23.81)$ & $20(25.64)$ & 0.802 & $0.91(0.42-1.96)$ & & NS \\
\hline \multicolumn{7}{|l|}{ Medical history } \\
\hline Hypertension $^{* *}$ & $47(75.81)$ & $59(75.64)$ & 0.982 & $1.01(0.46-2.20)$ & & NS \\
\hline Diabetes mellitus $^{* * *}$ & $10(16.13)$ & $10(12.82)$ & 0.578 & $1.31(0.51-3.37)$ & & NS \\
\hline Dyslipidemia & $21(33.87)$ & $29(37.18)$ & 0.685 & $0.87(0.43-1.74)$ & & NS \\
\hline Current smoking & $4(6.45)$ & $3(3.85)$ & 0.482 & $1.72(0.37-8.01)$ & & NS \\
\hline Atrial fibrillation $^{* *}$ & $33(53.23)$ & $43(55.13)$ & 0.822 & $0.93(0.47-1.81)$ & & NS \\
\hline \multicolumn{7}{|l|}{ Clinical and imaging data } \\
\hline NIHSS, median (Q1-Q3) & $17(11-21)$ & $20(17-24)$ & $<0.001$ & $0.88(0.83-0.94)$ & $0.90(0.83-0.97)$ & 0.013 \\
\hline 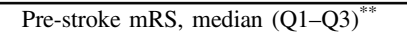 & $1(0-2)$ & $2(1-3)$ & $<0.001$ & $0.60(0.45-0.80)$ & $0.52(0.36-0.76)$ & $<0.001$ \\
\hline ASPECTS, median (Q1-Q3) & $9(8-10)$ & $9(7-10)$ & 0.159 & $1.23(0.97-1.55)$ & & NS \\
\hline \multicolumn{7}{|l|}{ Occlusion site } \\
\hline M1-MCA & $42(66.67)$ & $46(58.97)$ & 0.043 & ref & & NS \\
\hline Intracranial ICA & $9(14.29)$ & $24(30.77)$ & & $0.41(0.17-0.98)$ & & \\
\hline Other & $12(19.05)$ & $8(10.26)$ & & $1.64(0.61-4.41)$ & & \\
\hline \multicolumn{7}{|l|}{ Therapeutic data } \\
\hline IV r-tPA & $39(61.90)$ & $37(47.44)$ & 0.087 & $1.80(0.92-3.54)$ & & NS \\
\hline Recanalization & $51(80.95)$ & $55(70.51)$ & 0.154 & $1.78(0.80-3.94)$ & $3.65(1.32-10.09)$ & 0.013 \\
\hline \multicolumn{7}{|l|}{$\begin{array}{l}\text { Procedural times min, median (Q1-Q3, } \\
\text { IQR) }\end{array}$} \\
\hline Admission to IV r-tPA $(\mathrm{n}=61)$ & $42(30-50)$ & $42.5(27-60)$ & 0.857 & & & \\
\hline Admission to groin puncture $(\mathrm{n}=138)$ & $51(20-69)$ & $32(14-58)$ & 0.046 & $1.01(0.99-1.02)$ & & NS \\
\hline \multicolumn{7}{|l|}{ Complications } \\
\hline $\mathrm{ICH}(\mathrm{n}=129)$ & $7(11.11)$ & $20(30.30)$ & 0.007 & $0.29(0.11-0.74)$ & $0.24(0.08-0.75)$ & 0.013 \\
\hline Symptomatic ICH $(n=129)$ & $1(1.59)$ & $4(6.06)$ & 0.188 & & & \\
\hline Dissection $(\mathrm{n}=107)$ & $2(4.65)$ & $3(4.69)$ & 0.993 & & & \\
\hline Embolism $(\mathrm{n}=107)$ & $2(4.65)$ & $0(0.00)$ & 0.159 & & & \\
\hline Groin hematoma $(\mathrm{n}=107)$ & $3(6.98)$ & $7(10.94)$ & 0.490 & & & \\
\hline Perforation $(\mathrm{n}=107)$ & $0(0.00)$ & $1(1.56)$ & 0.412 & & & \\
\hline
\end{tabular}

ASPECTS = Alberta Stroke Program Early CT Score; ICA = internal carotid artery; IQR = interquartile range; IV r-tPA = intravenous recombinant tissue-type plasminogen activator; MCA = middle cerebral artery; $\mathrm{mRS}=$ modified Rankin scale; NIHSS = National Institutes of Health Stroke Scale; $\mathrm{NS}=$ not significant, $\mathrm{p}>0.05$, variables not retained in the stepwise logistic regression model.

*Multivariate logistic regression model using stepwise selection process including $(\mathrm{n}=119)$ age, gender, pre-stroke mRS, NIHSS, ASPECTS, hypertension, diabetes mellitus, hypercholesterolemia, current smoking, atrial fibrillation, site of occlusion, IV r-tPA, recanalization, admission to groin puncture time, and $\mathrm{ICH}$.

***1missing data $(\mathrm{n}=140)$.

procedural abandonment in cases of initial failure of recanalization. These findings suggest that alternative access approaches and the use of new thrombectomy devices should be evaluated in elderly patients in the hope of improving the rates of recanalization and consequently, good outcome. However, futile recanalization was common in our cohort (54.7\%), suggesting that factors other than artery reopening, such as baseline functional status and comorbidities, delays in recanalization, age-dependent infarct core thresholds, ${ }^{18}$ poor recruitment of collaterals, ${ }^{19}$ and poststroke complications are likely to influence outcome in elderly patients.

The presence of any ICH complicating reperfusion therapy was a significant predictor of poor outcome in our cohort, $55 \%$ of which received intravenous thrombolysis. Whether MT alone is superior to combined intravenous thrombolysis and MT with regard to functional outcome and hemorrhagic complications is 
not yet settled, ${ }^{20}$ but is of particular interest in elderly patients who may be at higher risk for $\mathrm{ICH}$ with thrombolysis. ${ }^{21}$ However, current recommendations are to combine intravenous thrombolysis and MT, with no exception given for patient age. ${ }^{22}$

Our study has several limitations. First, it is a retrospective study of selected patients treated in high-volume MT centers. Our population had a high median NIHSS score (19), a low median pre-stroke mRS score (1), and a high median ASPECT score (9), pointing to a likely selection bias. Second, no control arm of elderly patients (only treated with intravenous thrombolysis or not treated with any reperfusion therapy) was available for comparison. Third, the potential role of a firstpass-effect, found by others to be associated with favorable outcome in the elderly, ${ }^{7}$ was not analyzed. Fourth, our approach was exploratory in that we may not exclude residual confounding factors and the effect estimates in our results may not reflect total effects of the variables on outcome. Finally, the association of early limitation of care orders with mortality could not be evaluated.

In conclusion, our data suggest that MT is relatively safe in selected AIS patients aged $\geq 85$ years with procedural complications and symptomatic ICH, in line with those of previously published cohorts having a younger median patient age. Successful recanalization is achievable in about three-quarters of patients and is a predictor of good functional outcome and lower mortality at 90 days, supporting the utility of attempting to achieve recanalization in this population using MT. Importantly, only a minority of patients survived at 3 months with moderately severe or severe disability. However, lower rates of recanalization, higher mortality, and less frequent favorable functional outcomes can be expected at 90 days as compared to younger patients studied in the major MT trials. Withholding MT based on age alone does not seem justified, and therapeutic decisionmaking for elderly patients should be made on an individual basis with particular consideration of pre-stroke disability.

\section{Disclosures}

The authors report no disclosures.

\section{Statement of Authorship}

LD and AYP conceptualized and designed the study, collected the data, and drafted the manuscript. MB and ML collected the data and reviewed the manuscript for intellectual content. JH analyzed the data and reviewed the manuscript for intellectual content. CO conceptualized the study and reviewed the manuscript for intellectual content. WA, YB, ND, YD, OFE, LG, DI, GJ, FK, NN, JR, DR, CS and AW reviewed the manuscript for intellectual content.

\section{Supplementary Material}

To view supplementary material for this article, please visit https://doi.org/10.1017/cjn.2021.37.

\section{REFERENCES}

1. Goyal M, Menon BK, van Zwam WH, et al. HERMES collaborators. Endovascular thrombectomy after large-vessel ischaemic stroke: a meta-analysis of individual patient data from five randomised trials. Lancet. 2016;387:1723-31.
2. Jovin TG, Chamorro A, Cobo E, et al. Thrombectomy within 8 hours after symptom onset in ischemic stroke. N Engl J Med. 2015;372:2296-306.

3. Saver JL, Goyal M, Bonafe A, et al. SWIFT PRIME Investigators. Stent-retriever thrombectomy after intravenous t-PA vs t-PA alone in stroke. N Engl J Med. 2015;372:2285-95.

4. Bracard S, Ducrocq X, Mas JL, et al. THRACE investigators. Mechanical thrombectomy after intravenous alteplase vs alteplase alone after stroke (THRACE): a randomised controlled trial. Lancet Neurol. 2016;15:1138-47.

5. Jayaraman MV, Mc Taggart RA. Endovascular treatment of anterior circulation large vessel occlusion in the elderly. Front Neurol. 2018;8:713.

6. Alawieh A, Starke RM, Chatterjee AR, et al. Outcomes of endovascular thrombectomy in the elderly: a "real-world" multicenter study. J NeuroIntervent Surg. 2019;11:545-53.

7. Drouard-de-Rousiers E, Lucas L, Richard S, et al. Impact of reperfusion for nonagenarians treated by mechanical thrombectomy. Insights from the ETIS Registry. Stroke. 2019;50:3164-9.

8. Meyer L, Alexandrou M, Flottmann F, et al. Endovascular treatment of very elderly patients aged $\geq 90$ with acute ischemic stroke. J Am Heart Assoc. 2020;9(5):e014447.

9. Larrue V, von Kummer R, Müller A, et al. Risk factors for severe hemorrhagic transformation in ischemic stroke patients treated with recombinant tissue plasminogen activator: a secondary analysis of the European-Australasian Acute Stroke Study (ECASS II). Stroke. 2001;32:438-41.

10. Barber PA, Hill MD, Eliasziw M, et al ASPECTS Study Group. Imaging of the brain in acute ischaemic stroke: comparison of computed tomography and magnetic resonance diffusion-weighted imaging. J Neurol Neurosurg Psychiatry. 2005;76:1528-33.

11. Groot AE, Treurniet KM, Jansen IGH, et al. Endovascular treatment in older adults with acute ischemic stroke in the MR CLEAN Registry. Neurology 2020;95:e131-9.

12. Papanagiotou P, White CJ. Endovascular reperfusion strategies for acute stroke. JACC Cardiovasc Interv. 2016;9:307-17.

13. Hilditch CA, Nicholson P, Murad MH, et al. Endovascular management of acute stroke in the elderly: a systematic review and meta-analysis. AJNR Am J Neuroradiol. 2018;39:887-91.

14. Rangaraju S, Haussen D, Nogueira RG, Nahab F, Frankel M. Comparison of 3-month stroke disability and quality of life across modified Rankin scale categories. Interv Neurol. 2017;6:36-41.

15. Kurre W, Aguilar-Pérez M, Niehaus L, et al. Predictors of outcome after mechanical thrombectomy for anterior circulation large vessel occlusion in patients aged $\geq 80$ years. Cerebrovasc Dis. 2013;36:430-6.

16. Schramm P, Navia P, Papa R, et al. ADAPT technique with ACE68 and ACE64 reperfusion catheters in ischemic stroke treatment: results from the PROMISE study. J Neurointerv Surg. 2019;11:226-31.

17. Kastrup A, Brunner F, Hildebrandt H, et al. Endovascular therapy vs thrombolysis in patients with large vessel occlusions within the anterior circulation aged $\geq 80$ years. J Neurointerv Surg. 2018;10:1053-6.

18. Nogueira RG, Jadhav AP, Haussen DC, et al. Thrombectomy 6 to 24 hours after stroke with a mismatch between deficit and infarct. N Engl J Med 2018;378:11-21.

19. Lin MP, Brott TG, Liebeskind DS, et al. Collateral recruitment is impaired by cerebral small vessel disease. Stroke 2020;51:140410.

20. Yang P, Zhang Y, Zhang L, et al. Endovascular thrombectomy with or without intravenous alteplase in acute stroke. N Engl J Med 2020;382:1981-93.

21. Mazya M, Egido JA, Ford GA, et al. SITS Investigators. Predicting the risk of symptomatic intracerebral hemorrhage in ischemic stroke treated with intravenous alteplase: safe Implementation of Treatments in Stroke (SITS) symptomatic intracerebral hemorrhage risk score. Stroke. 2012;43:1524-1531.

22. Boulanger JM, Lindsay MP, Gubitz G, et al. Canadian stroke best practice recommendations for acute stroke management: prehospital, emergency department, and acute inpatient stroke care, 6th edition, update 2018. Int J Stroke. 2018;13:949-84. 